\title{
Vertebroplasty versus Kyphoplasty: A Comparison and Contrast
}

\begin{abstract}
The phrase "vertebroplasty versus kyphoplasty" evokes images of competitive procedures and groups of entrenched physicians locked in battle. Our involvement in the development and introduction of percutaneous vertebroplasty $(\mathrm{PV})$ and kyphoplasty (KP) in the United States has given us a unique perspective on the safety and efficacy of both procedures. We feel that PV and KP both offer potential benefit with acceptable safety when used by skilled physicians. The real hurdles now are to further assess and develop the appropriate indications, advantages, and shortcomings of each procedure. We must then select the appropriate method of therapy to maximally benefit our patients. Finally, all practitioners must venture beyond the dogma of their respective subspecialties and understand the full spectrum of tools and techniques that are available to treat vertebral compression fractures.
\end{abstract}

\section{History}

The history of the development of each procedure explains how a competitive environment has arisen between PV and KP, as with many of the physicians that utilize them. PV had its introduction in France, in 1984, by the interventional neuroradiologist Hervé Deramond (1). It was found useful for the treatment of pain associated with vertebral fracture resulting from benign and malignant tumors, as well as osteoporotic compression fractures $(1,2)$. Neuroradiologists in the United States began to use the technique in 1993, and the first U.S. case series reported was in 1997 (3). It has remained popular in the radiologic community.

Since the early clinical work, many reports have documented the biomechanical effects of PV and the pain relief resulting from this treatment for vertebral compression fractures $(1-3,7-21)$. A review of this literature shows that all reports reveal favorable results of pain relief and restoration of activities of daily living following PV. (A prospective, randomized series comparing $\mathrm{PV}$ to alternative therapy, however, has not yet been accomplished.) Clinical complications are rare in the hands of experienced operators. Some studies do report a higher risk of complications in patients with malignant disease, which includes myeloma and osteolytic metastases (myeloma is thought to be less risky than osteolytic malignancy).

The idea of attempting to treat a vertebral compression fracture with an inflatable balloon tamp (and thereby restore the vertebral body height and minimize the associated kyphotic deformity) was conceived by an orthopedic surgeon, Dr. Mark Reiley, in the early 1990s. The initial biomechanical investigations of the Kyphx inflatable balloon tamp (Kyphon Corporation, Sunnyvale, CA) were performed as a combined effort by this orthopedic surgeon and a neuroradiologist familiar with PV (4-6). The device was given 510k approval by the U.S. Food and Drug Administration as a "bone tamp." A randomized clinical trial that compared "kyphoplasty" to conservative medical management was attempted, but patient entry was slow and this initiative was ultimately abandoned in favor of a clinical registry tabulating the results of patients treated with KP. Thus, like PV, KP has not been tested in a comparison trial against conservative therapy. There are only a few peer-reviewed studies available to judge safety and efficacy of KP $(22,23)$. Case reports and opinion papers are also found, although they are few in number (24-28).

In one study, pain relief was found to be similar to that observed with PV, and the perioperative complication rate was $10 \%$, though no complications related to the procedure were claimed by the authors (22). An asymptomatic cement leak rate of $8.5 \%$ was observed. The authors enthusiastically reported height restoration, but analysis of their data reveals that the average height gained per vertebra treated was $3 \mathrm{~mm}$ at the center of vertebral endplate. This leaves open for debate the effectiveness of the KP procedure for predictably restoring vertebral height in vertebral compression fractures.

In another early series, all 15 patients who underwent 24 uncomplicated KP procedures for osteoporotic vertebral compression fractures that were present for an average duration of 14 weeks experienced immediate pain relief (23). The mean height restoration as measured on lateral radiographs was $1.5 \mathrm{~mm}$ in the posterior vertebral body, $4.7 \mathrm{~mm}$ in the midvertebral body, and $3.7 \mathrm{~mm}$ in the anterior vertebral body. In a larger series of 226 consecutive KP procedures, similar results with respect to height restoration were reported (24). A $1 \%$ complication rate in this series included one case of epidural hematoma that required surgical decompression, one case of spinal cord injury, and one case with transient adult respiratory distress syndrome. A multicenter registry of 1,439 patients with 2,194 treated fractures with KP showed an efficacy of $90 \%$ with respect to pain relief and a major complication rate of $0.2 \%$ per fracture (25).

Only one report is available with respect to $\mathrm{KP}$ as a treatment of pathologic vertebral compression fractures. In a series of 18 patients with multiple myeloma who underwent 55 uncomplicated KP procedures, significant pain relief was achieved in all patients (26). Height restoration was only reported in 39 treated levels and was listed as $34 \%$ (leaving in doubt the validity of this measurement for the entire treatment group).

The initial reports and editorials concerning KP were generated primarily in the orthopedic literature 


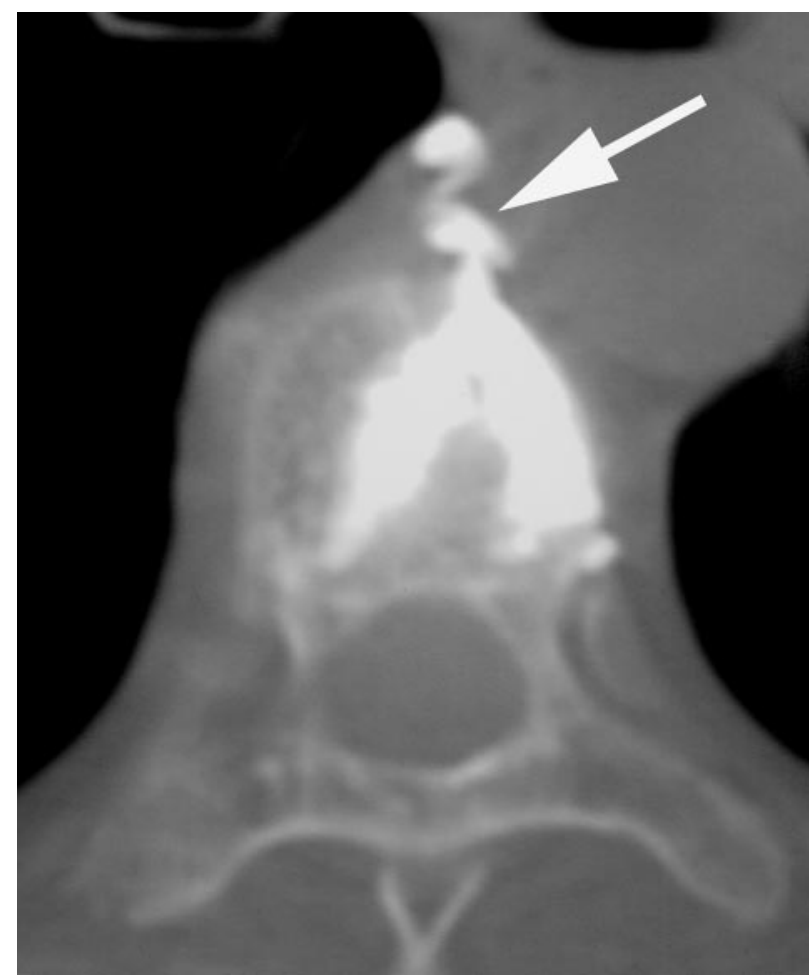

FIG 1. CT scan of a thoracic vertebra following KP. There was a lateral blowout fracture of the vertebra caused by balloon inflation and a large cement leak (arrow) into the mediastinum. The patient had severe pain requiring hospitalization and protracted analgesic therapy for weeks following therapy. (From JM Mathis. Percutaneous vertebroplasty. AJNR Am J Neuroradiol 2003; 24:1697-1706; by permission.)

and reflected an unqualified, positive opinion. Some of this literature seemed simply to echo marketing statements that were, as yet, unproved by clinical or laboratory investigation. The procedure, however, was not as well received in the radiologic community. This initial difference of opinion has not been substantially altered. KP has flourished in the surgical community, a group that has directly benefited from extensive marketing and educational support. Its members tend to see KP as a potential "high-dollar" replacement for PV. There has been growing competition for patients between the two groups that favor one or the other of these two procedures. Unfortunately, the competitive environment between radiologists and surgeons has been compounded by limited access to KP training courses for radiologists.

Substantial differences exist in the cost of PV and KP. The KP kit (without bone cement) is approximately $\$ 3,400$, whereas a PV kit (with bone cement) is less than $\$ 400$. Although not a requirement of the procedure, KP is often performed in the operating room with general anesthesia. The patients may be kept overnight in the hospital for observation. PV is usually performed with intravenous sedation only and a brief period of observation followed by discharge home after the procedure. All of these differences combine to make KP cost 10-20 times more than PV. This cost difference is acceptable only if there are proved, substantial positive benefits for the more ex- pensive procedure. KP marketing claims that these benefits include improved safety because of fewer symptomatic cement leaks and substantial height restoration with kyphosis reduction that might improve pulmonary and gastrointestinal function. Actual published data that address these claims directly are sparse, but an attempt here is made to compare and contrast results based on that information.

\section{Jargon versus Reality}

It seems that most physicians would agree that both $\mathrm{PV}$ and KP relieve the pain associated with vertebral compression fractures. This would seem logical, because KP relies on the same vertebral stabilization principal used in PV, the introduction of bone cement into a compromised vertebra. KP is even sometimes referred to as "balloon-assisted vertebroplasty" (29). Biomechanical data comparing the mechanical stabilization by PV and KP show similar results (4).

Beyond these basics, reality seems to be blurred by the jargon. Manufacturers and champions of any device describe their individual advantages. This has been no less true of KP proponents, who routinely point out the reduced likelihood for cement leaks

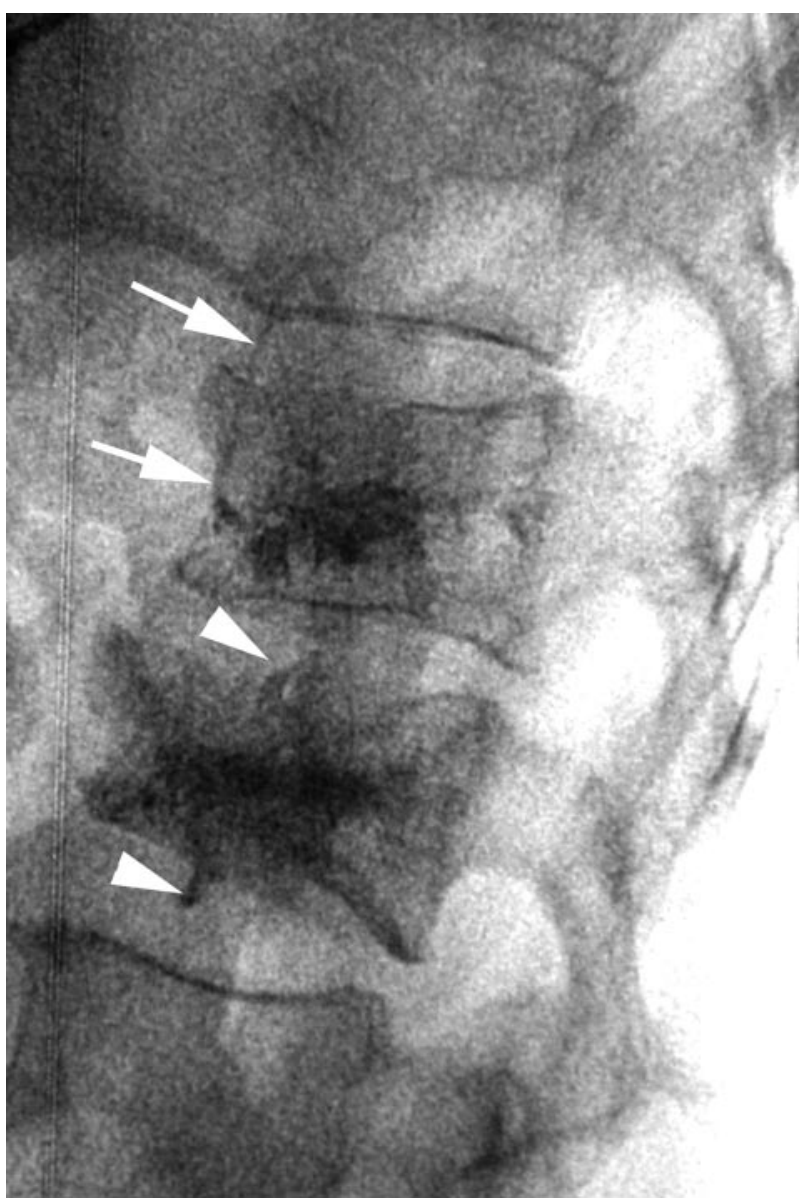

FIG 2. Radiograph following PV and KP, showing small, asymptomatic cement leaks at both levels. The PV level (above) had a small cement leak into an adjacent vein (arrows). The KP level (below) had small cement leaks into both adjacent disk levels (arrowheads). 

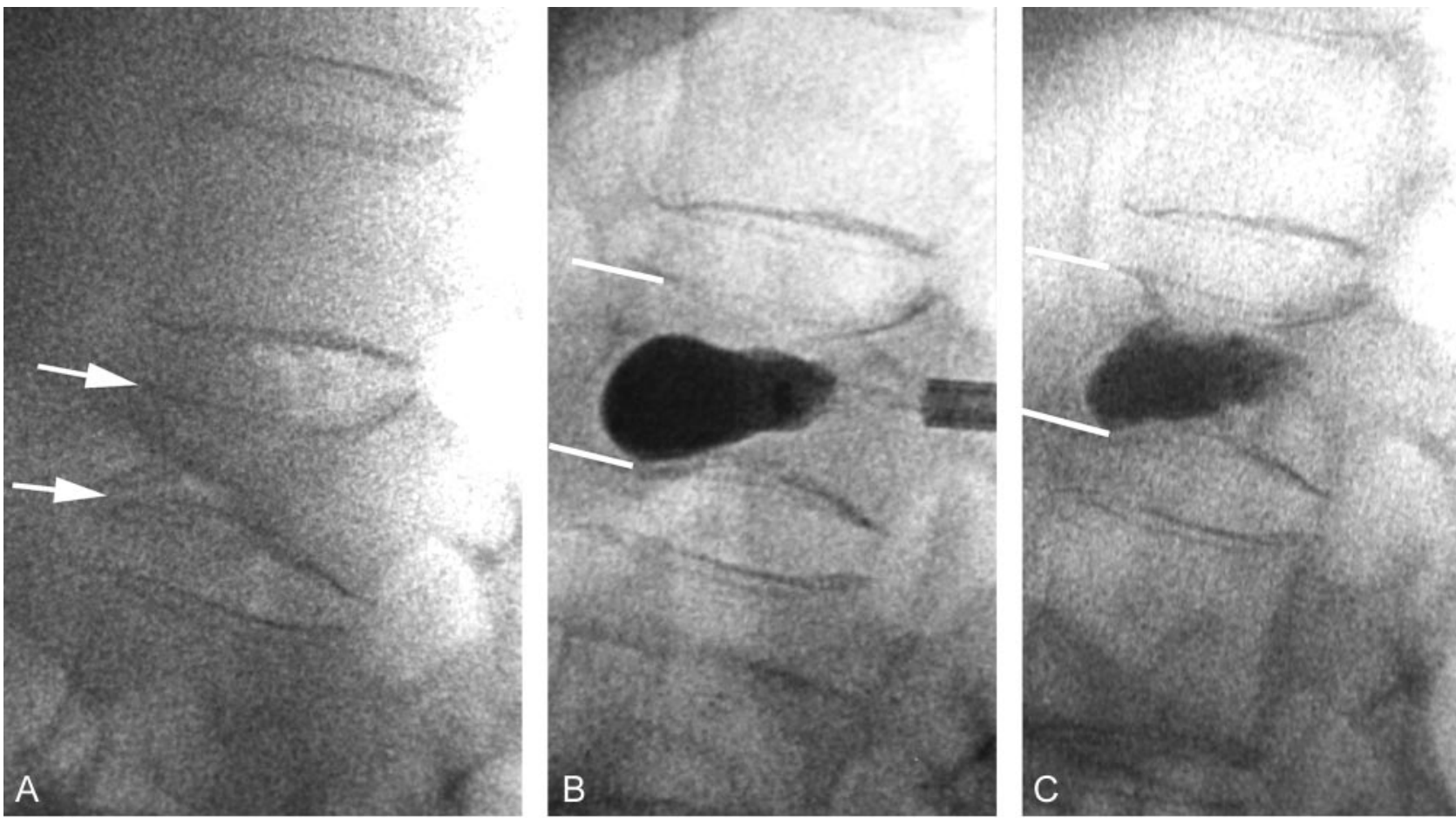

FIG 3. A, Compression fracture with anterior cleft before KP. Endplates are marked (arrows). The height is estimated at $50 \%$ of the height of the adjacent level above.

$B$, Fluoroscopic image showing balloon inflation during KP.

C, After cement injection, the height gain is approximately $4 \mathrm{~mm}$, or $25 \%$ of a vertebral height (when compared with the adjacent level above). There was essentially no kyphosis to start with, and this vertebrae had a cleft originally and therefore would be expected to be a good candidate for height restoration.

with this procedure compared with PV (30). This is alleged to occur because the injection of cement in $\mathrm{PV}$ is purportedly under "high pressure," whereas KP fills a void created by the bone tamp and is therefore "low pressure." For years this marketing-driven claim went unchallenged and is often repeated by physicians even though no scientific data existed that actually measured or compared the injection pressures with these devices. Recently, one group of investigators demonstrated quantitatively that, under usual operating conditions, "high-pressure" injections were not observed with any of these percutaneous vertebral fracture reduction procedures. In fact, the variables that seemed to influence intravertebral pressure measurements were the rate of injection and the size of the cannula. Higher intravertebral pressures were recorded with higher injection rates, larger bore systems, and when a metal trocar was used to drive cement through the cannula (31).

Lieberman et al reported a cement leak rate during KP of $8.6 \%$ (22). Fortunately, as with PV, most cement leaks were asymptomatic. KP reports have noted a very high cement leak incidence with PV, but they have failed to distinguish between symptomatic and asymptomatic leaks. When this is done, little difference seems to exist between the two procedures. Symptomatic cement leaks have occurred with both procedures (39) (Figs 1 and 2). Concern for patient safety prompted the FDA to issue a warning regard- ing the use of polymethylmethacrylate in both $\mathrm{PV}$ and KP in April 2003 (32).

Even in vitro, the capability of KP to reliably produce height restoration in fractures and compressed vertebral bodies remains controversial (Fig 3). Biomechanical evaluations by Belkoff and Mathis reported "significant" height restoration with KP compared with PV (5). Their investigation, however, looked only at vertebra that had a maximum height loss of $25 \%$. PV was noted to experience height recovery, but less than KP. The actual height gain difference achieved by KP was on the order of $3 \mathrm{~mm}$. Unfortunately, no in vitro investigations are available that determine whether this effect can be achieved, without destroying the vertebra, when compression is more severe that $25 \%$. Indeed, Lieberman et al's data, which show an average height restoration of approximately $3 \mathrm{~mm}$ per vertebra treated, suggest that KP may have a limited effect at height restoration in many patients (22). Alternatively, this limited clinical result could be due to indiscriminate patient selection. Patients in Lieberman et al's series, where the average symptom duration was 5.9 months, were treated relatively late after fracture and many of these patients could have experienced partial fracture healing before KP. Although these reports are anecdotal, it does seem that vertebral compression fractures that are treated closer to their date of incidence tend to experience more height restoration (22). Whereas the average height 

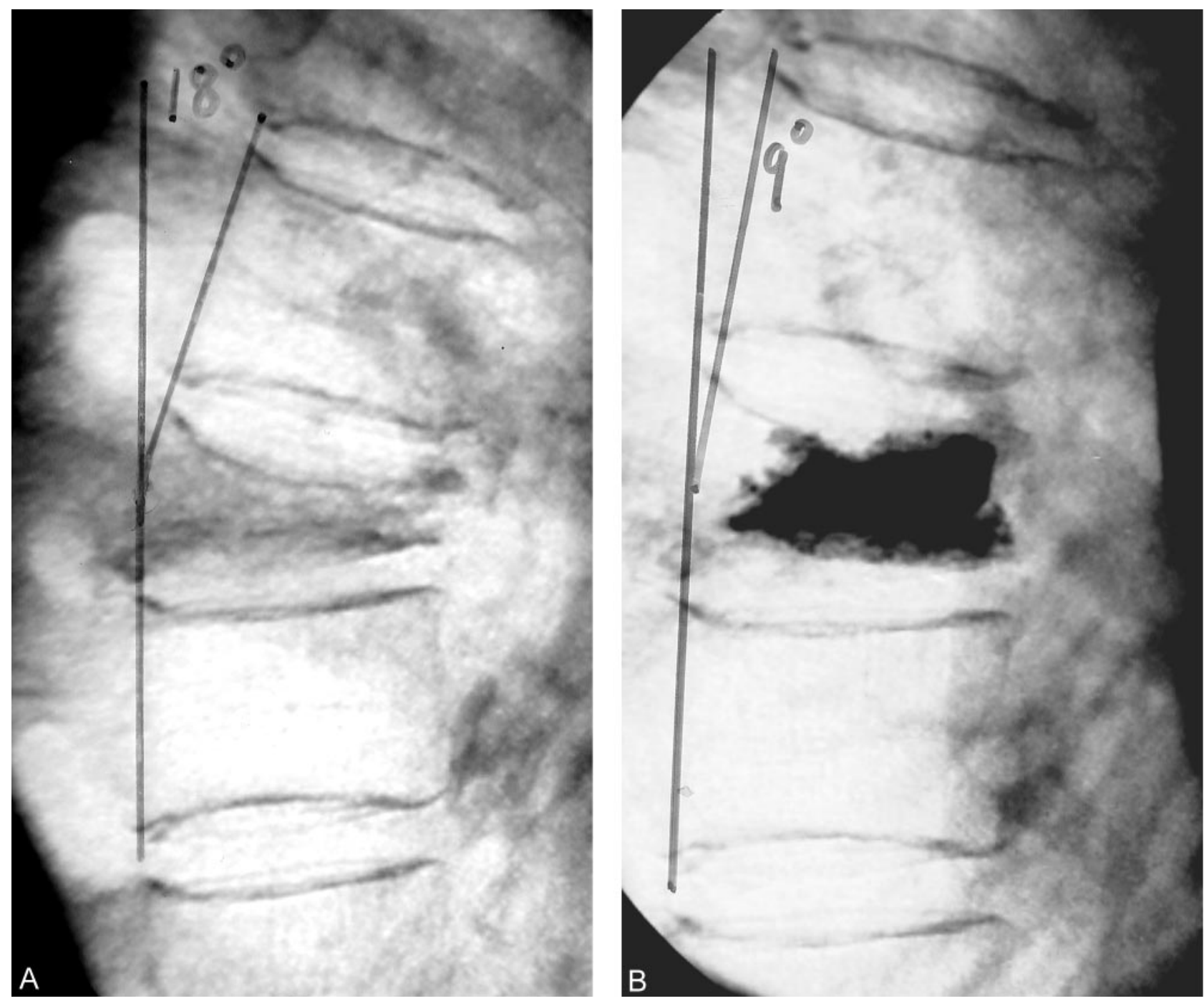

FIG 4. A, Radiograph of a compression fracture and $18^{\circ}$ of kyphosis.

$B$, Following PV, there is modest height gain, estimated at $3-4 \mathrm{~mm}$, and a reduction in kyphosis to $9^{\circ}$. (From $\mathrm{JM}$ Mathis. Percutaneous vertebroplasty. AJNR Am J Neuroradiol 2003; 24:1697-1706; by permission.)

restoration in a clinical setting ranges from 2.5 to 3.5 $\mathrm{mm}$ (33), no clinical trials are available that help us select those patients who will predictably get maximum height restoration by using KP. Pain relief seems less sensitive to "time since fracture." Pain relief in Lieberman et al's series was not adversely affected by treatment delay or the amount of height restoration achieved and was similar to that seen with PV (22).

Vertebral height restoration reported in some KP studies has been linked to correction of associated kyphotic deformity of the spine $(23,34)$. Theodorou et al reported an average kyphosis correction of $62.4 \% \pm 16.7 \%$ (23); however, patients who are pain free following PV or KP usually experience less muscle spasm and tend to stand straighter with the elimination of spine pain. Mathis demonstrated this effect in a PV case with 50\% kyphosis reduction after PV alone (39) (Fig 4). Teng et al reported kyphosis improvement following PV in 45 of 53 patients, with $49 \%$ having a kyphotic angle reduction of $5^{\circ}$ or more (41). Studies on the secondary benefits of kyphosis correction, such as improved pulmonary function, are not yet available. Obviously, this is another place where the corrections of both PV and KP need to be compared with control to determine the relative difference between the therapies.

What has often been neglected in the controversy regarding height restoration with $\mathrm{KP}$ is that $\mathrm{PV}$ can, in selected patients, also restore vertebral body height (Fig 4). Hiwatashi et al have shown that vertebral body height can be augmented by an average of $2.2 \mathrm{~mm}$ with PV simply by hyperextending the affected spinal segment (35). Similarly, McKiernan et al demonstrated dynamic fracture mobility in $35 \%$ of 65 vertebral compression fractures that they treated. Using PV alone, they reported that the "average anterior vertebral height increased 106\% compared with initial fracture height (absolute increase, $8.41 \pm 0.4 \mathrm{~mm}$ )" in patients with these mobile fractures. Their kyphotic angle reduction was $40 \%$ (40). If some height restoration can be expected from PV alone, the meager height recovery found in a series like that of Lieberman et al may be 
partially measuring the effect due to prone positioning rather than just that due to the balloon inflation.

\section{Authors' Opinions}

Without doubt, additional trials are needed to establish conclusively the effectiveness of both PV and KP compared with conservative medical therapy and each other. Attempts to perform these types of studies have been stymied by poor patient enrollment in the control arm of each trial. This occurs because of the positive public awareness about these augmentation techniques and the dramatic benefit that previously treated patients have experienced. Few patients are willing to accept the chance of undergoing a sham procedure when the available treatments seem reliably safe and effective. A randomized comparison of PV and KP would also help establish patient selection criteria and individual procedure advantages allowing physicians to better utilize these procedures to the patients' benefit. Until these data are available, we will likely continue to hear considerable jargon and relentless marketing claims about the relative safety and therapeutic advantages of each procedure.

We believe that both procedures relieve pain and can be performed with acceptable complication rates by prudent, well-trained physicians. We do note the large differential in cost of the procedures. If KP is going to be worthwhile, it should reliably produce significantly more height restoration than does PV. In our practices, we believe we employ KP differently but agree to its use when height restoration (beyond that usually achieved by PV) is feasible and would be beneficial. Our implementation of KP is driven by the "time since fracture" and is markedly different within our own ranks. One extreme requires fractures of 3 weeks or less (J.M.M.), while another tack includes fractures of less than 3 months (O.O.). Even with these guidelines, we are unable to assure large height restoration in all patients.

At present, we recommend that both procedures be available in the treatment armamentarium of all operators, thus allowing the physician, not the marketplace, to determine patient selection criteria. All vertebral compression fractures are not the same, and certain fracture subtypes may be more amenable to one or the other procedure. Regardless of which procedure is chosen, safety depends upon operator experience, excellent imaging equipment, and adequate cement opacification. Complications that have occurred with either procedure most often have been a result of poor operator judgment and experience or inadequate anatomic and cement visualization. Time and accumulated data will tell whether the promise of reliable height restoration with $\mathrm{KP}$ is realistic. Until then, careful use of either procedure should successfully relieve the pain associated with vertebral compression injury.

\section{John M. Mathis, A. Orlando Ortiz, and} Gregg H. Zoarski

\section{References}

1. Galibert P, Dermond H, Rosat P. [Preliminary note on the treatment of vertebral angioma by percutaneous acrylic vertebroplasty.] Neurochirurgie 1987;33:166-168

2. Bascoulergue Y, Duquesnel J, Leclercq R. Percutaneous injection of methyl methacrylate in the vertebral body for the treatment of various diseases: percutaneous vertebroplasty. [abstract] Radiology 1988; $169: 372$

3. Jensen ME, Evans AJ, Mathis JM, et al. Pecutaneous polymethylmethacrylate vertebroplasty in the treatment of osteoporotic vertebral compression fractures: technical aspects. AJNR Am J Neuroradiol 1997;18:1897-1904

4. Wilson DR, Myers ER, Mathis JM, et al. Effect of augmentation on the mechanics of vertebral wedge fractures. Spine 2000;25:158-165

5. Belkoff SM, Mathis JM, Fenton DC, et al. An ex vivo biomechanical evaluation of an inflatable bone tamp used in the treatment of compression fractures. Spine 2001;26:151-156

6. Belkoff SM, Mathis JM, Deramond H, Jasper LE. An ex vivo biomechanical evaluation of a hydroxyapatite cement for use with Kyphoplasty. AJNR Am J Neuroradiol 2001;22:1212-1216

7. Mathis JM, Barr JD, Belkoff SM, et al. Percutaneous vertebroplasty: a developing standard of care for vertebral compression fractures. AJNR Am J Neuroradiology 2001;22:373-381

8. Mathis JM, Eckel TS, Belkoff SM, Deramond H. Pecutaneous vertebroplasty: a therapeutic option for pain associated with vertebral compression fracture. J Back Musculoskel Rehab 1999;13: $11-17$

9. Mathis JM, Petri M, Naff N. Percutaneous vertebroplasty treatment of steroid-induced osteoporotic compression fractures. $\mathrm{Ar}$ thritis Rheum 1998;41:171-175

10. Belkoff SM, Mahoney M, Fenton DC, Mathis JM. An in vitro biomechanical evaluation of bone cements used in percutaneous vertebroplasty. Bone 1999; 25:23S-26S

11. Belkoff SM, Mathis JM, Erbe EM, Fenton DC. Biomechanical evaluation of a new bone cement for use in vertebroplasty. Spine 2000;25:1061-1064

12. Tohmeh AG, Mathis JM, Fenton DC, et al. Biomechanical efficacy of unipedicular versus bipedicular vertebroplasty for the management of osteoporotic compression fractures. Spine 1999;24:1772-1776

13. Belkoff SM, Mathis JM, Jasper LE, Deramond H. The biomechanics of vertebroplasty: the effect of cement volume on mechanical behavior. Spine 2001;26:1537-1541

14. Jasper LE, Deramond H, Mathis JM, Belkoff SM. The effect of monomer-to-powder ratio on the material properties of cranioplastic. Bone 1999;25:27S-29S

15. Jasper LE, Deramond H, Mathis JM, Belkoff SM. Material properties of various cements for the use with vertebroplasty. $J$ Mat Sci: Mat Med 2001;14:1-5

16. Belkoff SM, Mathis JM, Jasper LE, Deramond H. An ex vivo biomechanical evaluation of a hydroxyapatite cement for use with vertebroplasty. Spine 2001;26:1542-1546

17. Cotton A, Dewatre F, Cortet B. Percutaneous vertebroplasty for osteolytic metastases and myeloma. Radiology 1996;200:525-530

18. Weill A, Chiras J, Simon JM. Spinal metastases: indications for and results of percutaneous injection of acrylic surgical cement. Radiology 1996;199:241-247

19. Cyteval C, Sarrabere MP, Roux JO, et al. Acute osteoporotic vertebral collapse: open study on percutaneous injection of acrylic surgical cement in 20 patients. AJR Am J Roentgenol 1999;173: 1685-1690

20. Barr JD, Barr MS, Lemley TJ, McCann RM. Percutaneous vertebroplasty for pain relief and spinal stabilization. Spine 2000;25: 923-928

21. Zoarski GH, Snow P, Olan WJ, et al. Percutaneous vertebroplasty for osteoporotic compression fractures: quantitative prospective evaluation of long-term outcomes. J Vasc Interv Radiol 2002;13: 139-148

22. Lieberman IH, Dudeney S, Reinhardt MK, Bell G. Initial outcome and efficacy of "kyphoplasty" in the treatment of painful osteoporotic vertebral compression fractures. Spine 2001;26:1631-1638

23. Theodorou DJ, Theodorou SJ, Duncan TD, et al. Percutaneous balloon kyphoplasty for the correction of spinal deformity in painful vertebral body compression fractures. J Clin Imaging 2002;26:1-5

24. Lane JM, Girardi F, Parvaianen H, et al. Preliminary outcomes of 
the first $\mathbf{2 2 6}$ consecutive kyphoplasties for the fixation of painful osteoporotic vertebral compression fractures [abstract]. Osteoporosis Int (Suppl): 2000;11:S206

25. Garfin S, Lin G, Lieberman I, et al. Retrospective analysis of the outcomes of balloon kyphoplasty to treat vertebral body compression fracture (VCF) refractory to medical management. Eur Spine J 2001;10 (Suppl):S7

26. Dudeney S, Lieberman IH, Reinhardt MK, et al. Kyphoplasty in the treatment of osteolytic vertebral compression fractures as a result of multiple myeloma. J Clin Oncol 2002;20:2382-2387

27. Ledlie JT, Renfro M. Balloon kyphoplasty: one-year outcomes in vertebral body height restoration, chronic pain, and activity levels. J Neurosurg 2003;98(1 Suppl):36-42

28. Watts NB, Harris ST, Genant HK. Treatment of painful osteoporotic vertebral fractures with percutaneous vertebroplasty or kyphoplasty. Osteoporos Int 2001;12:429-437

29. Olan WJ. Kyphoplasty: Balloon-assisted vertebroplasty. ASNR Spine Symposium. Vancouver, BC. May 11-12, 2002:115-117

30. Phillips FM, Wetze FT, Lieberman I, Campbell-Hupp M. An in vivo comparison of the potential for extravertebral cement leak after vertebroplasty and kyphoplasty. Spine 2002;27:2173-2179

31. Agris JM, Zoarski GH, Stallmeyer MJB, Ortiz O. Intravertebral pressure during vertebroplasty: a study comparing multiple delivery systems. Presented at the annual meeting of the American Society of Spine Radiology, Scottsdale, AZ, February 19-23, 2003

32. FDA public health web notification. Complications related to the use of bone cement in treating compression fractures of the spine, April 2003; http://www.fda.gov/cdrh/safety/bonecement.html

33. Wong WH, Olan WJ, Belkoff SM. Balloon kyphoplasty. In Mathis JM, Deramond H, Belkoff SM, eds. Percutaneous vertebroplasty. New York: Springer-Verlag; 2002:109-124

34. Garfin SR, Yuan HA, Reiley MA. Kyphoplasty and vertebroplasty for the treatment of painful osteoporotic compression fractures. Spine 2001;26:1511-1515

35. Hiwatashi A, Moritani T, Numaguchi Y, Westesson PL. Increase in vertebral body height after vertebroplasty. AJNR Am J Neuroradiol 2003;24:185-189

36. Zoarski GH, Snow P, Olan WJ, et al. Percutaneous vertebroplasty: A to Z. Tech Vasc Interv Radiol 2002;5:223-228

37. Ortiz AO, Zoarski GH, Beckerman M. Kyphoplasty. Tech Vasc Interv Radiol 2002;5:239-249

38. Stallmeyer MJ, Zoarski GH, Obuchowski AM. Optimizing patient selection in percutaneous vertebroplasty. J Vasc Interv Radiol 2003; 14:683-696

39. Mathis JM. Percutaneous vertebroplasty: complication avoidance and technique optimization. AJNR Am J Neuroradiol 2003;24: 1697-1706

40. McKiernan F, Jensen R, Faciszewski T. The dynamic mobility of vertebral compression fractures. J Bone Miner Res 2003;18:24-29

41. Teng MMH, Wei CJ, Wei LC, et al. Kyphosis correction and height restoration effects of percutaneous vertebroplasty. AJNR Am Neuroradiol 2003;24:1893-1900 